\title{
Seven-level NPC Inverter-based Neuronal Direct Torque Control of the PMSM Drives with Regulation Speed Using Neural PI Controller
}

\author{
Habib Benbouhenni \\ Electrical Engineering Department, National Polytechnique School of Oran Maurice Audin, Oran, Algeria \\ Email address: \\ habib0264@gmail.com \\ To cite this article: \\ Habib Benbouhenni. Seven-level NPC Inverter-based Neuronal Direct Torque Control of the PMSM Drives with Regulation Speed Using \\ Neural PI Controller. International Journal of Intelligent Information Systems. Vol. 8, No. 5, 2019, pp. 85-96. \\ doi: $10.11648 /$ j.ijiis.20190805.11
}

Received: September 23, 2019; Accepted: October 18, 2019; Published: November 26, 2019

\begin{abstract}
In the scope of this work, a new structure of the direct torque control (DTC) technique scheme of permanent magnet synchronous motors (PMSMs) is proposed using a seven-level neutral point clamped (NPC) inverter and artificial neural networks (ANNs) controllers. This intelligent strategy was used to replace, on the one hand the integral proportional (PI) speed controller, on the other hand and the traditional switching table in order to reduce total harmonic distortion (THD) of voltage/current, stator flux ripple and electromagnetic torque ripples. The modeling and simulation of the proposed control scheme were carried out in Matlab/Simulink environment. The simulation results show that the proposed strategy scheme reduced harmonic distortion of stator voltage/current, stator flux and electromagnetic torque ripples compared to traditional DTC control scheme, DTC control scheme with space vector pulse width modulation (SVPWM) and three-level DTC control scheme. It was found that the stator current waveform becomes purely sinusoidal with a reduction in the harmonic distortion rate to $11.77 \%$.
\end{abstract}

Keywords: PMSMs, DTC, NPC, NNs, SVPWM, PI, THD

\section{Introduction}

PMSMs for Permanent Magnet Synchronous Motors are one of the most proper and efficient motors in electricity industry. these motors are good candidate for applications such as naval and space systems, electric vehicles and etc. The most important advantages of such motors are: high efficiency and power density, low loss, low maintenance cost, easy construction and etc [1]. Various control strategies have been proposed for regulate the electromagnetic torque of the PMSM drives. Most existing techniques used a field oriented control (FOC) [2], robust control [3], intelligent control [4], and DTC control [5]. Stator FOC control using proportionalintegral (PI) regulators is the traditional strategy used for PMSM drives. However, PI regulators performance is highly dependence on tuning of parameters and accurate tracking of angular information of stator voltage/flux. Moreover, the FOC control strategies need accurate values of machine parameters and rotor speed.
The DTC strategy has been introduced in the 1980s by Noguchi and Takahashi as an alternative to FOC control, with the two ofold objective of simplifying the control algorithms and achieving similar or even better performances [6]. In this strategy, two hysteresis comparators, namely flux and torque controllers are selected to determine the inverter instantaneous switching state. The DTC strategy is simple and alternative approach technique formulation that does not require decomposition into symmetrical components.

To ensure the robustness and good performance of the DTC strategy using hysteresis comparators, several approaches have been recently proposed. In [7], the authors proposed a new DTC strategy based on sliding mode controller (SMC) to control the PMSM. In [8], the authors proposed a DTC strategy with space vector modulation (SVM) to regulate the electromagnetic torque and stator flux ripples. DTC and fuzzy logic controlled (FLC) are combined to control PMSM [9]. SMC and fuzzy logic are combined to control PMSM [10]. In [11], a seven-level neural DTC with 
fuzzy speed controller of induction motor (IM) was presented. A four-level DTC control with ANN is proposed to regulate the stator flux and electromagnetic torque of the IM drives [12]. DTC and NN controller are combined to regulate the torque of PMSM [13]. In [14], the modified DTC strategy which is based on fractional sliding mode has been proposed. In this paper, we propose a new DTC control scheme based on ANN method of a PMSM fed by seven-level inverter. The simulation studies have performed with Matlab/Simulink board to performance testing of the proposed DTC algorithm. The section II is dedicated to the modeling of the PMSM machine. In section III of this paper, the basic principles of the conventional DTC control scheme has shortly introduced. In section IV, detailed information of the proposed strategy based on ANN controller has presented. Section V presents the simulation results of the both strategies. Finally, conclusion has given in section VI.

\section{Model of PMSM}

The mathematical model of the three-phase PMSM can be expressed in the $(q-d)$ synchronous rotating frame by the following nonlinear equations $[15,16]$ :

$$
\Psi_{d s}=L_{d} I_{d s}+\Psi_{f}
$$

Where: ds: is the stator flux linkage of $d$-axis.

$\mathrm{I}_{\mathrm{ds}}:$ is the stator current of $d$-axis.

$f:$ is the permanent magnet flux.

$\mathrm{L}_{\mathrm{d}}$ : is the inductance of $d$-axis.

$$
\Psi_{q s}=L_{q} I_{q s}
$$

Where: Lq: is the inductance of $q$-axis. Isq: is the stator current of $q$-axis.

$$
V_{d s}=R_{s} I_{d s}+\frac{d \Psi_{d s}}{d t}-p \boldsymbol{W}_{r} \Psi_{q s}
$$

Where: Vsd: is the stator voltage of $d$-axis.

$\mathrm{sd}$ : is the stator flux linkage of $d$-axis.

Rs: is the stator resistance.

Vsq: is the stator voltage of $q$-axis.

$$
V_{q s}=R_{s} I_{q s}+\frac{d \Psi_{q s}}{d t}-p \mathcal{W}_{r} \Psi_{d s}
$$

Where: Vsq: is the stator voltage of $q$-axis. wr: is the rotor mechanical speed.

The electromagnetic torque equation is expressed as:

$$
T_{e}=\frac{3}{2} p\left[\Psi_{d s} I_{q s}+I_{d s} \Psi_{q s}\right]
$$

Where: $p$ : is the number of pole paire.

Te: is the electromagnetic torque

So the dynamic equation is given as:

$$
T_{e}=T_{r}+J \cdot \frac{d \Omega}{d t}+f \cdot \Omega
$$

Where: $\Omega$ : is the mechanical rotor speed.

$\mathrm{J}:$ is the moment of inertia.

Tr: is the motor torque load.

$\mathrm{f}$ : is the coefficient of viscous friction.

\section{Traditional DTC Control}

The goal of the DTC control is to control the electromagnetic torque and stator flux by the application of the optimal voltage vector synthesized from the determination of the suitable sequences to be applied to the power switches devices of the two-level inverter [17]. The principle of the DTC strategy is illustrated in Figure 1. The estimated value of electromagnetic torque and stator flux are compared with references values using the hysteresis comparators [18].

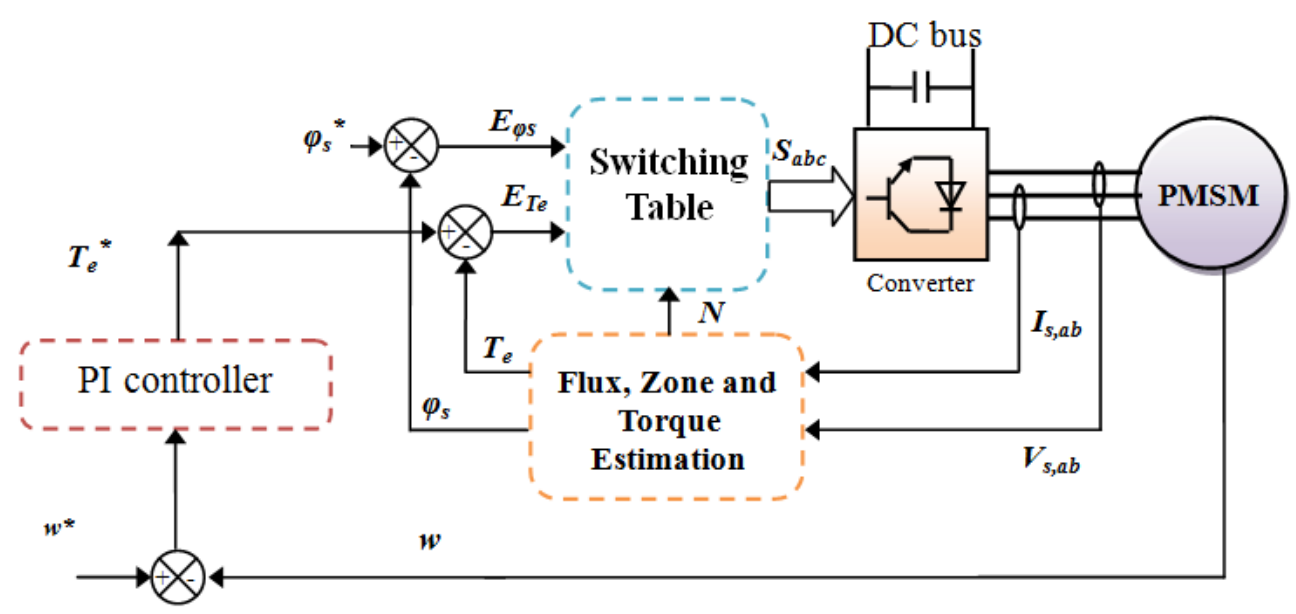

Figure 1. Block diagram of the DTC control for PMSM.

The stator flux can be obtained, in a stationary reference frame $(\alpha, \beta)$, as follows $[19,20]$ : 
The stator flux amplitude is given by:

$$
\left\{\begin{aligned}
\Phi_{\alpha S}= & \int_{0}^{t}\left(v_{\alpha S}-R_{S} i_{\alpha S}\right) d t \\
& \Phi_{\beta S}=\int_{0}^{t}\left(v_{\beta S}-R_{S} i_{\beta S}\right) d t
\end{aligned}\right.
$$

The stator flux angle is calculated by:

$$
\Phi_{S}=\sqrt{\Phi_{\alpha S}^{2}+\Phi_{\beta S}^{2}}
$$

The stator flux angle is calculated by:

$$
\theta_{S}=\operatorname{arctg}\left(\frac{\Phi \beta_{s}}{\Phi \alpha_{S}}\right)
$$

The stator voltage is calculated by:

$$
V_{s}=V_{\alpha s}+V_{\beta s}
$$

And:

$$
\left\{\begin{array}{l}
V_{\alpha s}=R_{s} I_{\alpha s}+\frac{d \Psi_{\alpha s}}{d t} \\
V_{\beta s}=R_{s} I_{\beta s}+\frac{d \Psi_{\beta s}}{d t}
\end{array}\right.
$$

The stator current is calculated by:

$$
\left\{\begin{array}{c}
I_{\alpha s}=\sqrt{\frac{2}{3}} I_{a} \\
I_{\beta s}=\frac{1}{\sqrt{2}}\left(I_{b}-I_{c}\right)
\end{array}\right.
$$

With: Is $=$ Is $\alpha+\mathrm{j}$ Is $\beta$

Electromagnetic torque (Te) can be calculated using the components of the estimated flux and measured currents:

$$
T e=\frac{3}{2} p\left[\Phi \alpha_{s i} \beta_{s}-\Phi \beta_{s i} \alpha_{s}\right]
$$

The representation of the space voltage vectors of the traditional inverter for all switching states is given by Figure 2.

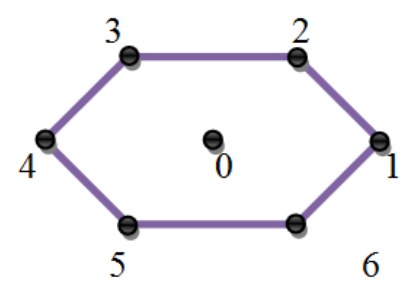

Figure 2. Two-level inverter vectors representations.

In traditional DTC a two-level hysteresis comparator is used for the stator flux (HSF) and a three-level hysteresis comparator for the electromagnetic torque (HET) (See Figure 3 and Figure 4). Finally, based on the values of constants HSF and HET and the position of the stator flux (six region control), the inverter switching algorithm is as shown in Table 1 [21].

Table 1. Switching table of traditional DTC control.

\begin{tabular}{llllllll}
\hline $\mathbf{N}$ & & $\mathbf{1}$ & $\mathbf{2}$ & $\mathbf{3}$ & $\mathbf{4}$ & $\mathbf{5}$ & $\mathbf{6}$ \\
\hline HSF & $\mathbf{H E T}$ & & & & & \\
& 1 & 2 & 3 & 4 & 5 & 6 & 1 \\
1 & 0 & 1 & 2 & 3 & 4 & 5 & 6 \\
& -1 & 6 & 1 & 2 & 3 & 4 & 5 \\
& 1 & 3 & 4 & 5 & 6 & 1 & 2 \\
0 & 0 & 4 & 5 & 6 & 1 & 2 & 3 \\
& -1 & 5 & 6 & 1 & 2 & 3 & 4 \\
\hline
\end{tabular}

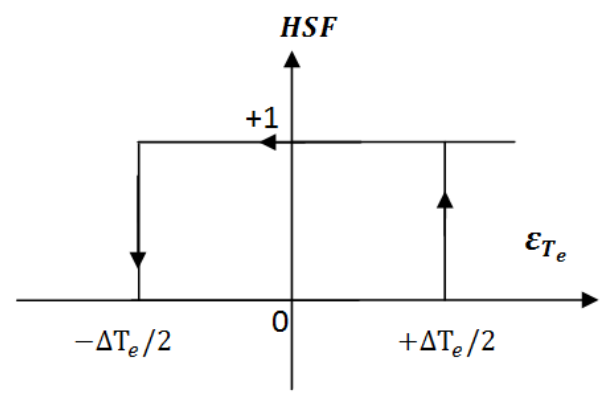

Figure 3. Stator flux hysteresis comparator.

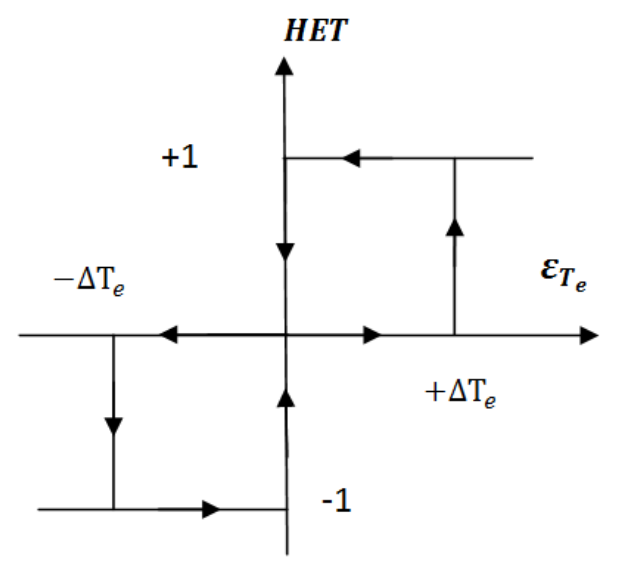

Figure 4. Electromagnetic torque hysteresis comparator.

\section{Seven-level DTC Control}

The DTC strategy is one of the actively researched control which is based on decoupled control of torque and stator flux. Among all techniques of torque control of PMSM, DTC achieves robust and fast torque response without the need of speed or position sensors, coordinate transformation, current regulators and PWM pulse generation. In this paper, the feeding of the PMSM is assured by seven-level NPC inverter. However, the NPC inverter is one of the most interesting solutions, to increase power levels and voltage. The representation of the space voltage vectors of a seven-level NPC inverter for all switching states is given by Figure 5. Tables 2-5 shows the proposed look-up table for seven-level DTC control in terms of the electromagnetic torque 
hysteresis comparators output, the stator flux hysteresis comparator output and the zone $(\mathrm{N})$ of stator flux vector. In this proposed DTC algorithm a three-level hysteresis comparator is used for the stator flux and a 13-level hysteresis comparator for the torque is shown in Figure 6 and Figure 7 respectfully.

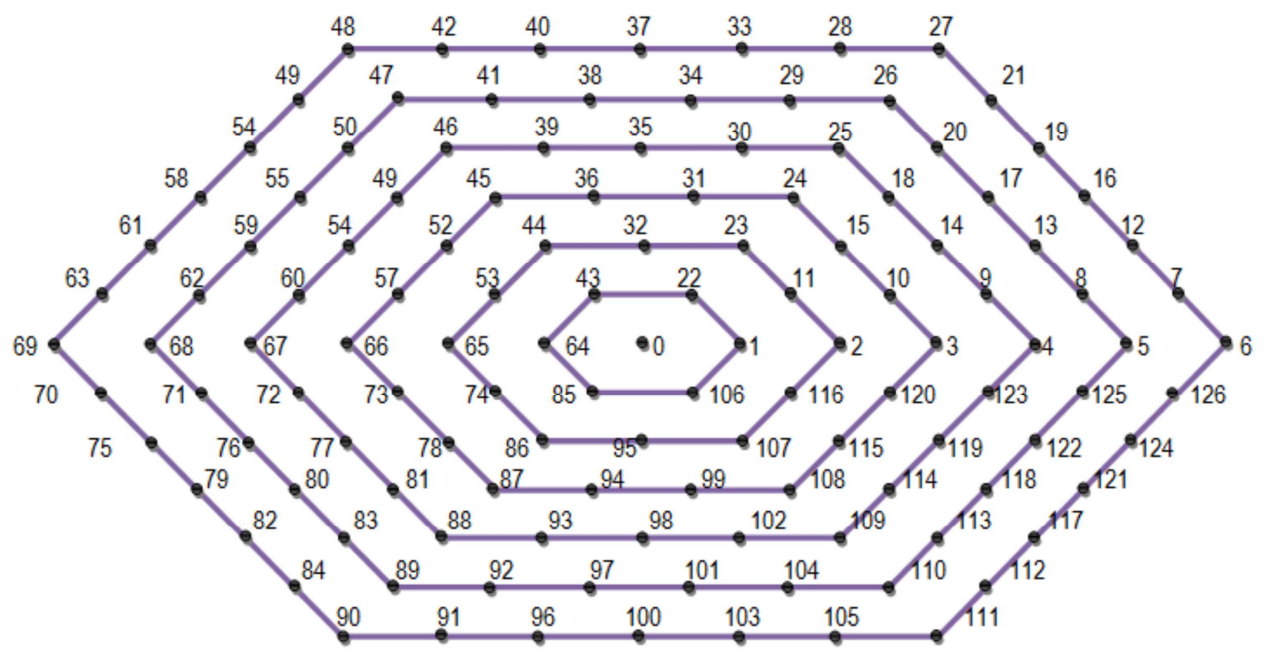

Figure 5. Space vector diagram of seven-level NPC inverter.

Table 2. Switching table of seven-level DTC control (N1 to N13).

\begin{tabular}{|c|c|c|c|c|c|c|c|c|c|c|c|c|c|c|}
\hline $\begin{array}{l}\mathbf{N} \\
\text { HSF }\end{array}$ & HET & 1 & 2 & 3 & 4 & 5 & 6 & 7 & 8 & 9 & 10 & 11 & 12 & 13 \\
\hline \multirow{14}{*}{1} & 6 & 27 & 28 & 33 & 37 & 40 & 42 & 48 & 49 & 54 & 58 & 61 & 63 & 69 \\
\hline & 5 & 21 & 27 & 28 & 33 & 37 & 40 & 42 & 48 & 49 & 54 & 58 & 61 & 63 \\
\hline & 4 & 19 & 21 & 27 & 28 & 33 & 37 & 40 & 42 & 48 & 49 & 54 & 58 & 61 \\
\hline & 3 & 16 & 19 & 21 & 27 & 28 & 33 & 37 & 40 & 42 & 48 & 49 & 54 & 58 \\
\hline & 2 & 12 & 16 & 19 & 21 & 27 & 28 & 33 & 37 & 40 & 42 & 48 & 49 & 54 \\
\hline & 1 & 7 & 12 & 16 & 19 & 21 & 27 & 28 & 33 & 37 & 40 & 42 & 48 & 49 \\
\hline & 0 & 6 & 7 & 12 & 16 & 19 & 21 & 27 & 28 & 33 & 37 & 40 & 42 & 48 \\
\hline & -1 & 126 & 6 & 7 & 12 & 16 & 19 & 21 & 27 & 28 & 33 & 37 & 40 & 42 \\
\hline & -2 & 124 & 126 & 6 & 7 & 12 & 16 & 19 & 21 & 27 & 28 & 33 & 37 & 40 \\
\hline & -3 & 121 & 124 & 126 & 6 & 7 & 12 & 16 & 19 & 21 & 27 & 28 & 33 & 37 \\
\hline & -4 & 117 & 121 & 124 & 126 & 6 & 7 & 12 & 16 & 19 & 21 & 27 & 28 & 33 \\
\hline & -5 & 112 & 117 & 121 & 124 & 126 & 6 & 7 & 12 & 16 & 19 & 21 & 27 & 28 \\
\hline & -6 & 111 & 112 & 117 & 121 & 124 & 126 & 6 & 7 & 12 & 16 & 19 & 21 & 27 \\
\hline & 6 & 37 & 40 & 42 & 48 & 49 & 54 & 58 & 61 & 63 & 69 & 70 & 75 & 79 \\
\hline \multirow{11}{*}{0} & 5 & 37 & 40 & 42 & 48 & 49 & 54 & 58 & 61 & 63 & 69 & 70 & 75 & 79 \\
\hline & 4 & 33 & 37 & 40 & 42 & 48 & 49 & 54 & 58 & 61 & 63 & 69 & 70 & 75 \\
\hline & 3 & 33 & 37 & 40 & 42 & 48 & 49 & 54 & 58 & 61 & 63 & 69 & 70 & 75 \\
\hline & 2 & 28 & 33 & 37 & 40 & 42 & 48 & 49 & 54 & 58 & 61 & 63 & 69 & 70 \\
\hline & 1 & 28 & 33 & 37 & 40 & 42 & 48 & 49 & 54 & 58 & 61 & 63 & 69 & 70 \\
\hline & 0 & 0 & 0 & 0 & 0 & 0 & 0 & 0 & 0 & 0 & 0 & 0 & 0 & 0 \\
\hline & -1 & 100 & 103 & 105 & 111 & 112 & 117 & 121 & 124 & 126 & 6 & 7 & 12 & 16 \\
\hline & -2 & 100 & 103 & 105 & 111 & 112 & 117 & 121 & 124 & 126 & 6 & 7 & 12 & 16 \\
\hline & -3 & 96 & 100 & 103 & 105 & 111 & 112 & 117 & 121 & 124 & 126 & 6 & 7 & 12 \\
\hline & -4 & 96 & 100 & 103 & 105 & 111 & 112 & 117 & 121 & 124 & 126 & 6 & 7 & 12 \\
\hline & -5 & 91 & 96 & 100 & 103 & 105 & 111 & 112 & 117 & 121 & 124 & 126 & 6 & 7 \\
\hline \multirow{14}{*}{-1} & -6 & 91 & 96 & 100 & 103 & 105 & 111 & 112 & 117 & 121 & 124 & 126 & 6 & 7 \\
\hline & 6 & 48 & 49 & 54 & 58 & 61 & 63 & 69 & 70 & 75 & 79 & 82 & 84 & 90 \\
\hline & 5 & 47 & 47 & 50 & 55 & 59 & 62 & 68 & 68 & 71 & 76 & 80 & 83 & 89 \\
\hline & 4 & 46 & 46 & 51 & 56 & 56 & 60 & 67 & 67 & 72 & 77 & 77 & 81 & 88 \\
\hline & 3 & 45 & 45 & 52 & 52 & 57 & 57 & 66 & 66 & 73 & 73 & 78 & 78 & 87 \\
\hline & 2 & 5 & 5 & 8 & 13 & 17 & 20 & 26 & 26 & 29 & 34 & 38 & 41 & 47 \\
\hline & 1 & 68 & 68 & 71 & 76 & 80 & 83 & 89 & 89 & 92 & 97 & 101 & 104 & 110 \\
\hline & 0 & 26 & 26 & 29 & 34 & 38 & 41 & 47 & 47 & 50 & 55 & 59 & 62 & 68 \\
\hline & -1 & 88 & 88 & 93 & 98 & 98 & 102 & 109 & 109 & 114 & 119 & 119 & 123 & 4 \\
\hline & -2 & 89 & 89 & 92 & 97 & 101 & 104 & 110 & 110 & 113 & 118 & 122 & 125 & 5 \\
\hline & -3 & 90 & 91 & 96 & 100 & 103 & 105 & 111 & 112 & 117 & 121 & 124 & 126 & 6 \\
\hline & -4 & 84 & 90 & 91 & 96 & 100 & 103 & 105 & 111 & 112 & 117 & 121 & 124 & 126 \\
\hline & -5 & 82 & 84 & 90 & 91 & 96 & 100 & 103 & 105 & 111 & 112 & 117 & 121 & 124 \\
\hline & -6 & 79 & 82 & 84 & 90 & 91 & 96 & 100 & 103 & 105 & 111 & 112 & 117 & 121 \\
\hline
\end{tabular}


Table 3. Switching table of seven-level DTC control (N14 to N30).

\begin{tabular}{|c|c|c|c|c|c|c|c|c|c|c|c|c|c|c|c|c|c|c|}
\hline $\begin{array}{l}\text { N } \\
\text { HSF } \\
\end{array}$ & HET & 14 & 15 & 16 & 17 & 18 & 19 & 20 & 21 & 22 & 23 & 24 & 25 & 26 & 27 & 28 & 29 & 30 \\
\hline \multirow{14}{*}{1} & 6 & 70 & 75 & 79 & 82 & 84 & 90 & 91 & 96 & 100 & 103 & 105 & 111 & 112 & 117 & 121 & 124 & 126 \\
\hline & 5 & 69 & 70 & 75 & 79 & 82 & 84 & 90 & 91 & 96 & 100 & 103 & 105 & 111 & 112 & 117 & 121 & 124 \\
\hline & 4 & 63 & 69 & 70 & 75 & 79 & 82 & 84 & 90 & 91 & 96 & 100 & 103 & 105 & 111 & 112 & 117 & 121 \\
\hline & 3 & 61 & 63 & 69 & 70 & 75 & 79 & 82 & 84 & 90 & 91 & 96 & 100 & 103 & 105 & 111 & 112 & 117 \\
\hline & 2 & 58 & 61 & 63 & 69 & 70 & 75 & 79 & 82 & 84 & 90 & 91 & 96 & 100 & 103 & 105 & 111 & 112 \\
\hline & 1 & 54 & 58 & 61 & 63 & 69 & 70 & 75 & 79 & 82 & 84 & 90 & 91 & 96 & 100 & 103 & 105 & 111 \\
\hline & 0 & 49 & 54 & 58 & 61 & 63 & 69 & 70 & 75 & 79 & 82 & 84 & 90 & 91 & 96 & 100 & 103 & 105 \\
\hline & -1 & 48 & 49 & 54 & 58 & 61 & 63 & 69 & 70 & 75 & 79 & 82 & 84 & 90 & 91 & 96 & 100 & 103 \\
\hline & -2 & 42 & 48 & 49 & 54 & 58 & 61 & 63 & 69 & 70 & 75 & 79 & 82 & 84 & 90 & 91 & 96 & 100 \\
\hline & -3 & 40 & 42 & 48 & 49 & 54 & 58 & 61 & 63 & 69 & 70 & 75 & 79 & 82 & 84 & 90 & 91 & 96 \\
\hline & -4 & 37 & 40 & 42 & 48 & 49 & 54 & 58 & 61 & 63 & 69 & 70 & 75 & 79 & 82 & 84 & 90 & 91 \\
\hline & -5 & 33 & 37 & 40 & 42 & 48 & 49 & 54 & 58 & 61 & 63 & 69 & 70 & 75 & 79 & 82 & 84 & 90 \\
\hline & -6 & 28 & 33 & 37 & 40 & 42 & 48 & 49 & 54 & 58 & 61 & 63 & 69 & 70 & 75 & 79 & 82 & 84 \\
\hline & 6 & 82 & 84 & 90 & 91 & 96 & 100 & 103 & 105 & 111 & 112 & 117 & 121 & 124 & 126 & 6 & 7 & 12 \\
\hline \multirow{11}{*}{0} & 5 & 82 & 84 & 90 & 91 & 96 & 100 & 103 & 105 & 111 & 112 & 117 & 121 & 124 & 126 & 6 & 7 & 12 \\
\hline & 4 & 79 & 82 & 84 & 90 & 91 & 96 & 100 & 103 & 105 & 111 & 112 & 117 & 121 & 124 & 126 & 6 & 7 \\
\hline & 3 & 79 & 82 & 84 & 90 & 91 & 96 & 100 & 103 & 105 & 111 & 112 & 117 & 121 & 124 & 126 & 6 & 7 \\
\hline & 2 & 75 & 79 & 82 & 84 & 90 & 91 & 96 & 100 & 103 & 105 & 111 & 112 & 117 & 121 & 124 & 126 & 6 \\
\hline & 1 & 75 & 79 & 82 & 84 & 90 & 91 & 96 & 100 & 103 & 105 & 111 & 112 & 117 & 121 & 124 & 126 & 6 \\
\hline & 0 & 0 & 0 & 0 & 0 & 0 & 0 & 0 & 0 & 0 & 0 & 0 & 0 & 0 & 0 & 0 & 0 & 0 \\
\hline & -1 & 19 & 21 & 27 & 28 & 33 & 37 & 40 & 42 & 48 & 49 & 54 & 58 & 61 & 63 & 69 & 70 & 75 \\
\hline & -2 & 19 & 21 & 27 & 28 & 33 & 37 & 40 & 42 & 48 & 49 & 54 & 58 & 61 & 63 & 69 & 70 & 75 \\
\hline & -3 & 16 & 19 & 21 & 27 & 28 & 33 & 37 & 40 & 42 & 48 & 49 & 54 & 58 & 61 & 63 & 69 & 70 \\
\hline & -4 & 16 & 19 & 21 & 27 & 28 & 33 & 37 & 40 & 42 & 48 & 49 & 54 & 58 & 61 & 63 & 69 & 70 \\
\hline & -5 & 12 & 16 & 19 & 21 & 27 & 28 & 33 & 37 & 40 & 42 & 48 & 49 & 54 & 58 & 61 & 63 & 69 \\
\hline \multirow{14}{*}{-1} & -6 & 12 & 16 & 19 & 21 & 27 & 28 & 33 & 37 & 40 & 42 & 48 & 49 & 54 & 58 & 61 & 63 & 69 \\
\hline & 6 & 91 & 96 & 100 & 103 & 105 & 111 & 112 & 117 & 121 & 124 & 126 & 6 & 7 & 12 & 16 & 19 & 21 \\
\hline & 5 & 89 & 92 & 97 & 101 & 104 & 110 & 110 & 113 & 118 & 122 & 125 & 5 & 5 & 8 & 13 & 17 & 20 \\
\hline & 4 & 88 & 93 & 98 & 98 & 102 & 109 & 109 & 114 & 119 & 119 & 123 & 4 & 4 & 9 & 14 & 14 & 18 \\
\hline & 3 & 87 & 94 & 94 & 99 & 99 & 108 & 108 & 115 & 115 & 120 & 120 & 3 & 3 & 10 & 10 & 15 & 15 \\
\hline & 2 & 47 & 50 & 55 & 59 & 62 & 68 & 68 & 71 & 76 & 80 & 83 & 89 & 89 & 92 & 97 & 101 & 104 \\
\hline & 1 & 110 & 113 & 118 & 122 & 125 & 5 & 5 & 8 & 13 & 17 & 20 & 26 & 26 & 29 & 34 & 38 & 41 \\
\hline & 0 & 68 & 71 & 76 & 80 & 83 & 89 & 89 & 92 & 97 & 101 & 104 & 110 & 110 & 113 & 118 & 122 & 125 \\
\hline & -1 & 4 & 9 & 14 & 14 & 18 & 25 & 25 & 30 & 35 & 35 & 39 & 46 & 46 & 51 & 56 & 56 & 60 \\
\hline & -2 & 5 & 8 & 13 & 17 & 20 & 26 & 26 & 29 & 34 & 38 & 41 & 47 & 47 & 50 & 55 & 59 & 62 \\
\hline & -3 & 7 & 12 & 16 & 19 & 21 & 27 & 28 & 33 & 37 & 40 & 42 & 48 & 49 & 54 & 58 & 61 & 63 \\
\hline & -4 & 6 & 7 & 12 & 16 & 19 & 21 & 27 & 28 & 33 & 37 & 40 & 42 & 48 & 49 & 54 & 58 & 61 \\
\hline & -5 & 126 & 6 & 7 & 12 & 16 & 19 & 21 & 27 & 28 & 33 & 37 & 40 & 42 & 48 & 49 & 54 & 58 \\
\hline & -6 & 124 & 126 & 6 & 7 & 12 & 16 & 19 & 21 & 27 & 28 & 33 & 37 & 40 & 42 & 48 & 49 & 54 \\
\hline
\end{tabular}

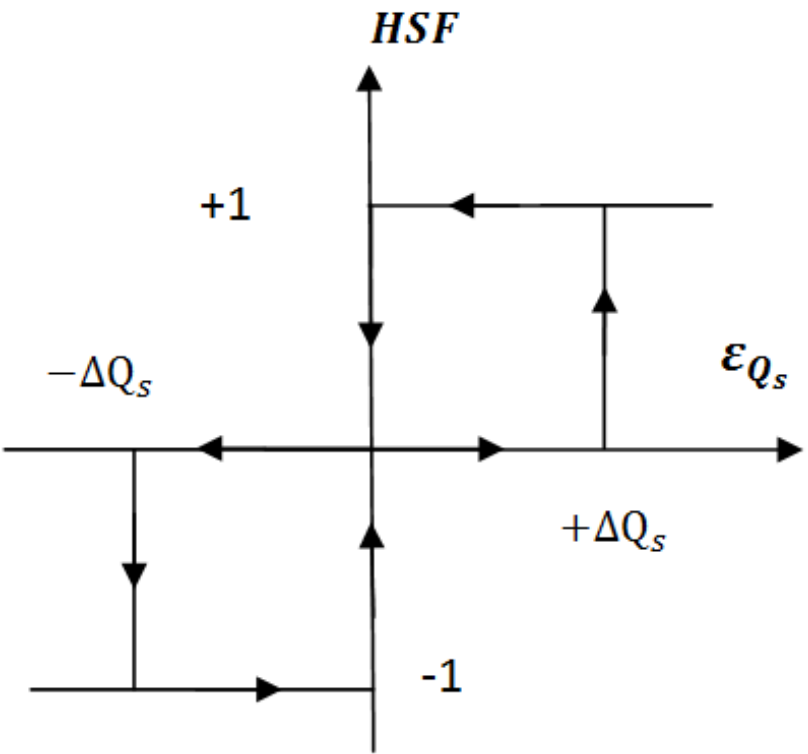

Figure 6. Stator flux hysteresis comparator.

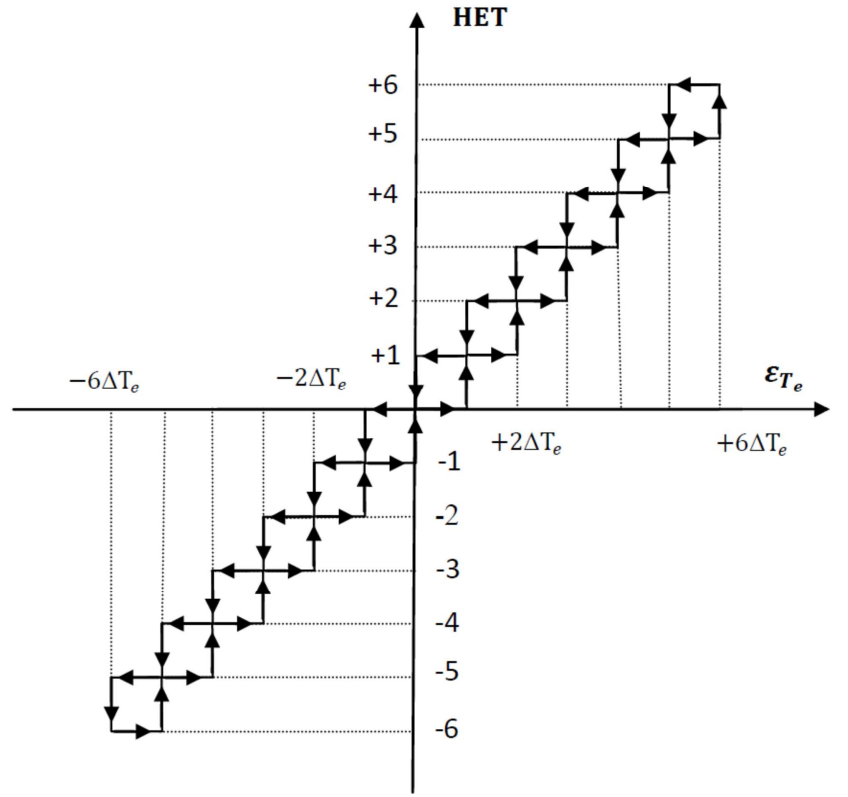

Figure 7. Torque hysteresis comparator. 


\section{Seven-level DTC with ANN Controller}

In order to improve the seven-level DTC performances a complimentary use of ANN controller is proposed. The principle of neural direct torque control is similar to conventional DTC strategy. The difference is using an ANN controller to replace the switching table and classical PI regulator of speed. As shown in Figure 8. This proposed DTC control is simple control scheme and easy to implement. This proposed control scheme reduced harmonic distortion of stator current, electromagnetic torque and stator flux ripples compared to traditional DTC strategy.

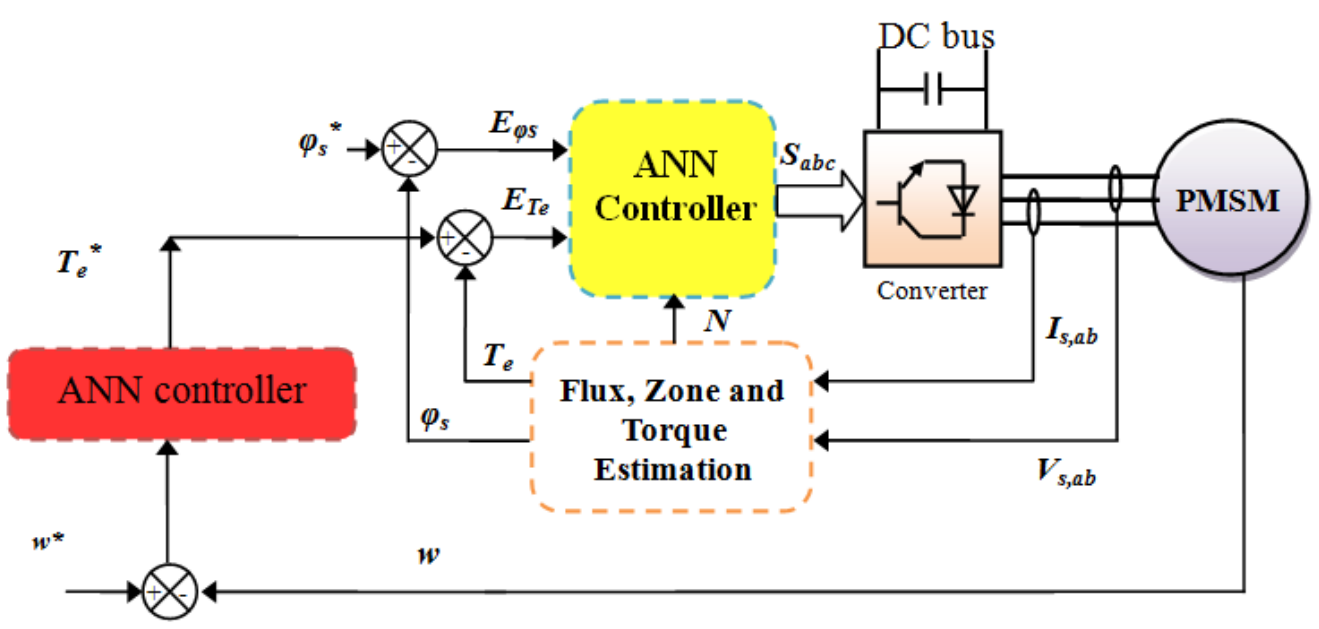

Figure 8. Block diagram of the neural DTC for PMSM.

Table 4. Switching table of seven-level DTC control (N31 to N36).

\begin{tabular}{|c|c|c|c|c|c|c|c|}
\hline \multicolumn{2}{|l|}{$\mathbf{N}$} & \multirow{2}{*}{31} & \multirow{2}{*}{32} & \multirow{2}{*}{33} & \multirow{2}{*}{34} & \multirow{2}{*}{35} & \multirow{2}{*}{36} \\
\hline HSF & HET & & & & & & \\
\hline \multirow{13}{*}{1} & 6 & 6 & 7 & 12 & 16 & 19 & 21 \\
\hline & 5 & 126 & 6 & 7 & 12 & 16 & 19 \\
\hline & 4 & 124 & 126 & 6 & 7 & 12 & 16 \\
\hline & 3 & 121 & 124 & 126 & 6 & 7 & 12 \\
\hline & 2 & 117 & 121 & 124 & 126 & 6 & 7 \\
\hline & 1 & 112 & 117 & 121 & 124 & 126 & 6 \\
\hline & 0 & 111 & 112 & 117 & 121 & 124 & 126 \\
\hline & -1 & 105 & 111 & 112 & 117 & 121 & 124 \\
\hline & -2 & 103 & 105 & 111 & 112 & 117 & 121 \\
\hline & -3 & 100 & 103 & 105 & 111 & 112 & 117 \\
\hline & -4 & 96 & 100 & 103 & 105 & 111 & 112 \\
\hline & -5 & 91 & 96 & 100 & 103 & 105 & 111 \\
\hline & -6 & 90 & 91 & 96 & 100 & 103 & 105 \\
\hline \multirow{12}{*}{0} & 6 & 16 & 19 & 21 & 27 & 28 & 33 \\
\hline & 5 & 16 & 19 & 21 & 27 & 28 & 33 \\
\hline & 4 & 12 & 16 & 19 & 21 & 27 & 28 \\
\hline & 3 & 12 & 16 & 19 & 21 & 27 & 28 \\
\hline & 2 & 7 & 12 & 16 & 19 & 21 & 27 \\
\hline & 1 & 7 & 12 & 16 & 19 & 21 & 27 \\
\hline & 0 & 0 & 0 & 0 & 0 & 0 & 0 \\
\hline & -1 & 79 & 82 & 84 & 90 & 91 & 96 \\
\hline & -2 & 79 & 82 & 84 & 90 & 91 & 96 \\
\hline & -3 & 75 & 79 & 82 & 84 & 90 & 91 \\
\hline & -4 & 75 & 79 & 82 & 84 & 90 & 91 \\
\hline & -5 & 70 & 75 & 79 & 82 & 84 & 90 \\
\hline \multirow{11}{*}{-1} & -6 & 27 & 28 & 33 & 37 & 40 & 42 \\
\hline & 6 & 27 & 28 & 33 & 37 & 40 & 42 \\
\hline & 5 & 26 & 26 & 29 & 34 & 38 & 41 \\
\hline & 4 & 25 & 25 & 30 & 35 & 35 & 39 \\
\hline & 3 & 24 & 24 & 31 & 31 & 36 & 36 \\
\hline & 2 & 110 & 110 & 113 & 118 & 122 & 125 \\
\hline & 1 & 47 & 47 & 50 & 55 & 59 & 62 \\
\hline & 0 & 5 & 5 & 8 & 13 & 17 & 20 \\
\hline & -1 & 67 & 67 & 72 & 77 & 77 & 81 \\
\hline & -2 & 68 & 68 & 71 & 76 & 80 & 83 \\
\hline & -3 & 69 & 70 & 75 & 79 & 82 & 84 \\
\hline
\end{tabular}

\begin{tabular}{llllllll}
\hline $\mathbf{N}$ & & \multirow{2}{*}{$\mathbf{3 1}$} & $\mathbf{3 2}$ & $\mathbf{3 3}$ & $\mathbf{3 4}$ & $\mathbf{3 5}$ & $\mathbf{3 6}$ \\
\cline { 1 - 5 } $\mathbf{H S F}$ & $\mathbf{H E T}$ & & & & & & \\
& -4 & 63 & 69 & 70 & 75 & 79 & 82 \\
& -5 & 61 & 63 & 69 & 70 & 75 & 79 \\
& -6 & 58 & 61 & 63 & 69 & 70 & 75 \\
\hline
\end{tabular}

\subsection{ANN Control Based Speed Controller}

The block diagram for neural based proportional-integral (PI) regulator is shown in Figure 9. The neural PI (PIN) controller design is based on intuition and simulation. The training used is that of the retropropagation of LevenbergMarquardt (LM). The Table 5 shows the parameters of ANN controller.

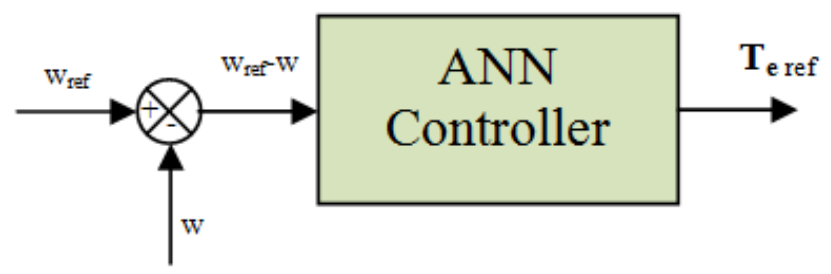

Figure 9. Neural control of speed regulation.

Table 5. Parameters of the LM algorithm.

\begin{tabular}{ll}
\hline ParametersoftheLM & Values \\
\hline Number of hidden layer & 8 \\
TrainParam.Lr & 0.02 \\
TrainParam.show & 50 \\
TrainParam.eposh & 300 \\
Coeff of acceleration of convergence $(\mathrm{mc})$ & 0.9 \\
TrainParam.goal & 0 \\
TrainParam.mu & 0.9 \\
Functions of activation & Tensing, Purling, gensim \\
\hline
\end{tabular}

Such a neural controller contains three layers: input layers, hidden layers and output layers. Each layer is composed of 
several neurons. The block diagram of the ANN controller of the speed regulation is given by Figure 10. The structure of layer 1 and layer 2 is shown in Figure 11 and Figure 12 respectively.

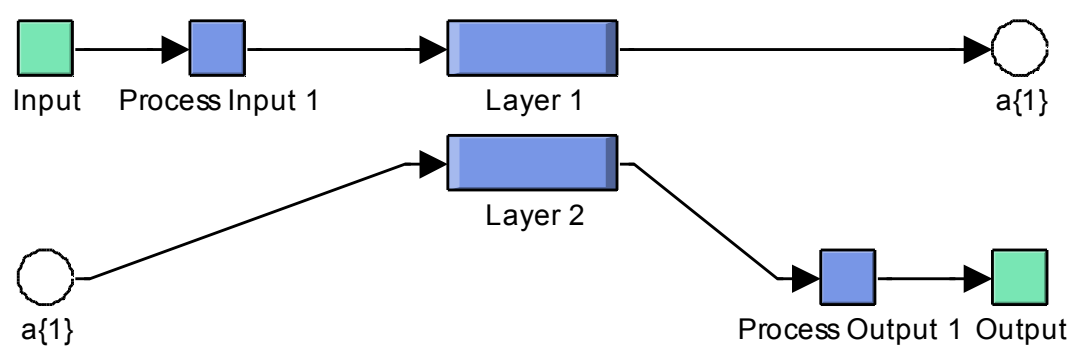

Figure 10. Block diagram of the neural speed regulator.

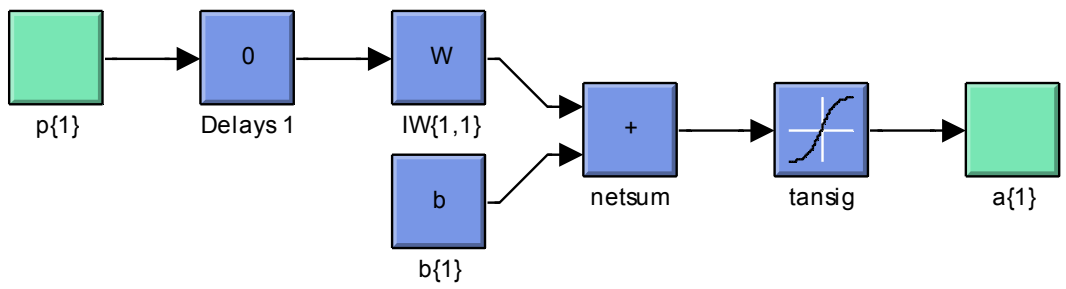

Figure 11. Layer 1.

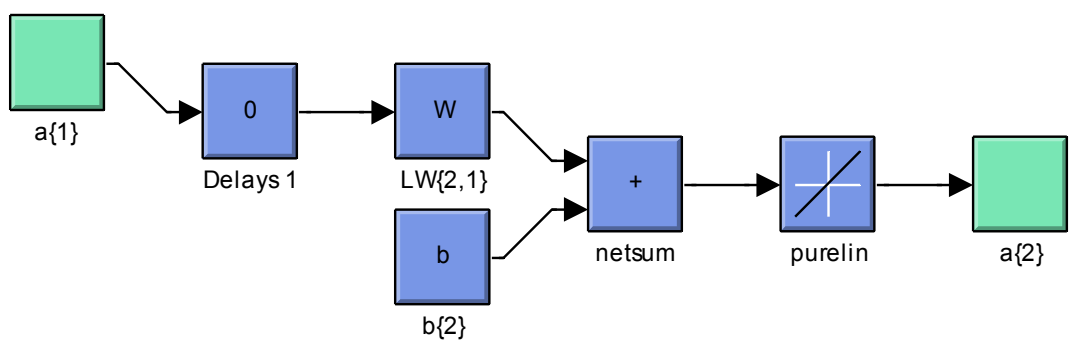

Figure 12. Layer 2.

\subsection{ANN Based Switching Table}

In the conventional DTC strategy, stator flux and electromagnetic torque can be directly controlled by using hysteresis comparators and switching table. In this approach, we replaced the switching table by a single ANN controller with stator flux hysteresis comparator, torque hysteresis comparator and sector as inputs. The switching ( $\mathrm{Sa}, \mathrm{Sb}$ and $\mathrm{Sc}$ ) of the inverter will be the control output. The proposed ANN controller is the retropropagation of LevenbergMarquardt (LM). The parameters of the LM algorithm is shown in Table 6 . The structure of neural switching table is illustrated in the Figure 13.

Table 6. Parameters of the LM for switching table.

\begin{tabular}{ll}
\hline Parameters & Values \\
\hline Number of hidden layer & 30 \\
TrainParam.Lr & 0.02 \\
TrainParam.show & 50 \\
TrainParam.eposh & 3000 \\
Coeff of acceleration of convergence (mc) & 0.9 \\
TrainParam.goal & 0 \\
TrainParam.mu & 0.9 \\
Functions of activation & Tensing, Purling, gensim \\
\hline
\end{tabular}

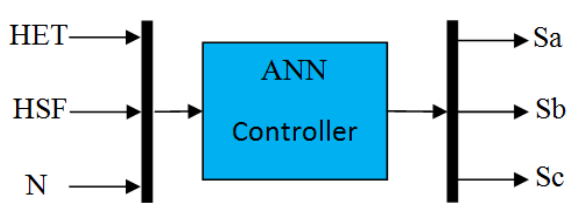

Figure 13. Blockdiagramoftheneuralswitchingtable.

\section{Simulation Results}

The simulation results of seven-level DTC-ANN with neural speed controller (DTC-ANN-PIN) of sensorless PMSM are compared with traditional DTC (DTC-2N) strategy. The performance analysis is done with harmonic distortion of stator current, sector, torque, flux and speed. The stator flux and torque references used in the simulation results of the classical DTC and DTC-ANN with the neural speed controller are $0.3 \mathrm{wb}$ and $5 \mathrm{~N} . \mathrm{m} \rightarrow-5 \mathrm{~N} . \mathrm{m}$ respectively. The machine is running at $100 \mathrm{rad} / \mathrm{s} \rightarrow-90 \mathrm{rad} / \mathrm{s} \rightarrow 100 \mathrm{rad} / \mathrm{s}$.

The PMSM used in this case study is a $1,5 \mathrm{Kw}, 220 / 380 \mathrm{~V}$, three poles, $50 \mathrm{~Hz}$, with the following parameters: $\mathrm{Rs}=1.4 \Omega$, $\mathrm{Lq}=0.0066 \mathrm{H}, \mathrm{Ld}=0.0058 \mathrm{H}, \mathrm{f}=0.1546 \mathrm{~Wb}$.

The system has the following mechanical parameters: $\mathrm{J}=$ $0.00176 \mathrm{Kg} . \mathrm{m}^{2}, \mathrm{fr}=0.00038818 \mathrm{Nm} / \mathrm{s}$. 
A. Reference tracking test (RTT)

Figures 20-21 shows the THD of stator current of the PMSM obtained using FFT (Fast Fourier Transform) method for conventional DTC strategy and seven-level DTC-ANN with neural speed controller one respectively. It can be clearly observed that the THD is minimized for seven-level DTC-ANN-PIN when compared to conventional DTC control scheme. Table 7 shows the comparative analysis of THD value.

For the conventional DTC strategy and seven-level DTCANN with PIN controller, the speed, stator flux and electromagnetic torque, tracks almost perfectly their references values (see Figures 14-16).

Electromagnetic torque response comparing curves are

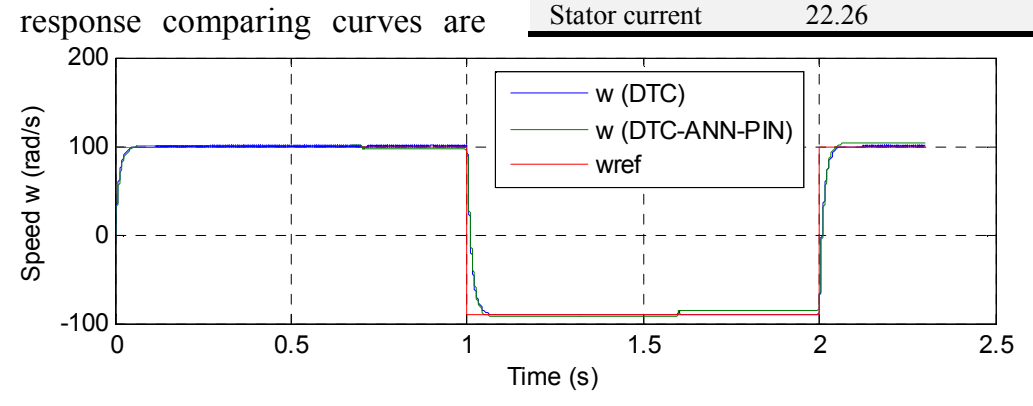

Figure 14. Speed.

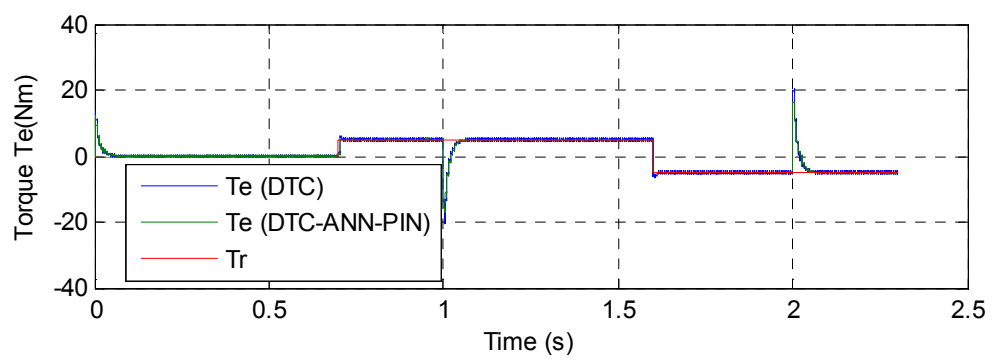

Figure 15. Torque.

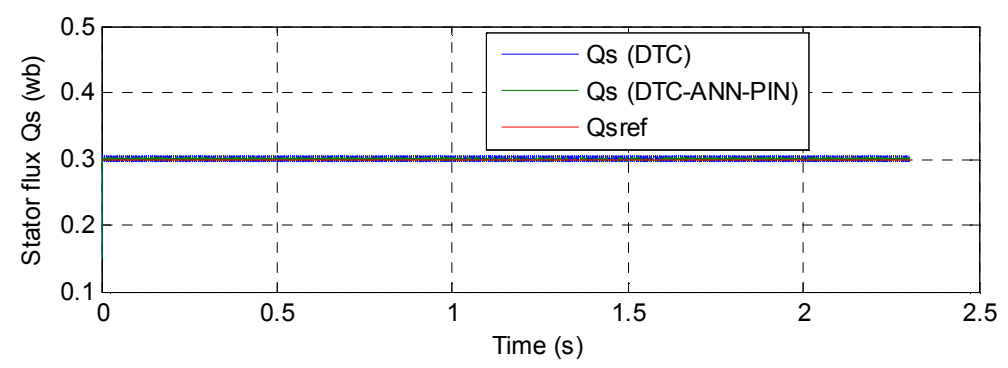

Figure 16. Stator flux.

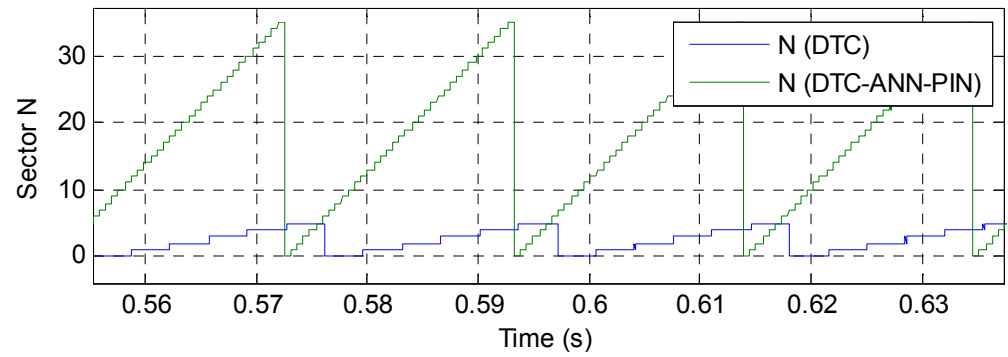

Figure 17. Sector. shown in Figure 17. See figure the torque ripple is ignificantly reduced when the seven-level DTC-ANN with

Figure 18 shows the flux responses of both the conventional DTC strategy and seven-level DTC-ANN with PIN controller. It is found that the proposed DTC exhibits smooth response and lesser ripple in flux as compared to the conventional DTC strategy and three-level DTC control scheme in ref. [22].

Table 7. Comparative analysis of THD value (RTT).

\begin{tabular}{lll}
\hline & THD (\%) & \\
\cline { 2 - 3 } & DTC & DTC-ANN-PIN \\
\hline Stator current & 22.26 & 11.77 \\
\hline
\end{tabular}




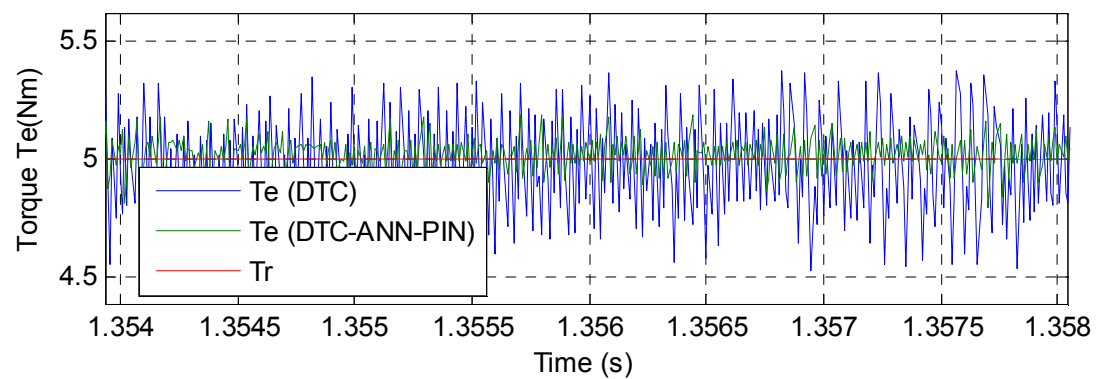

Figure 18. Zoom in the torque.

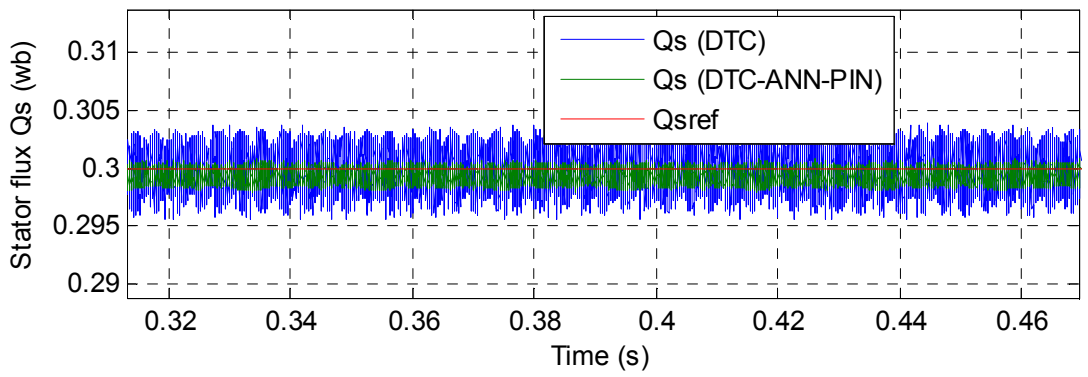

Figure 19. Zoom in the stator flux.
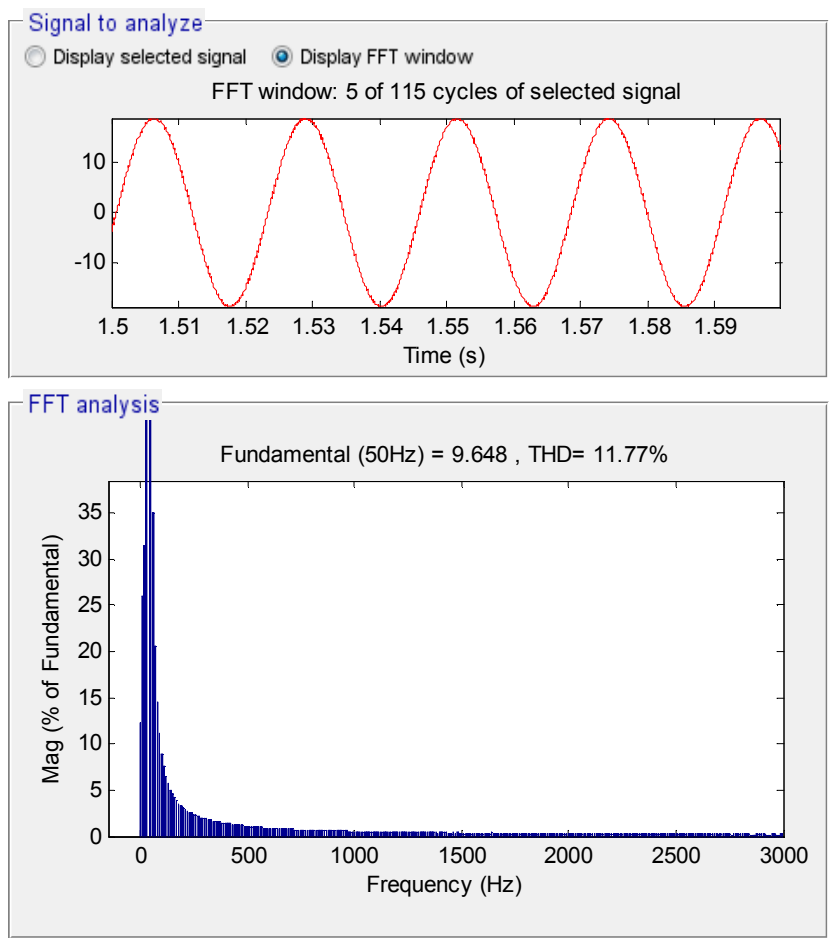

Figure 20. Spectrum harmonic of stator current (DTC).

B. Robustness test (RT)

In this section, the nominal value of the $R s$ is multiplied by 2 , the values of inductances $L d$ and $L q$ are multiplied by 0.5 . Simulation results are presented in Figures 22-27. As it's shown by these figures, these variations present an apparent effect on the stator flux and electromagnetic torque curves and that the effect appears more significant for the conventional DTC strategy compared to seven-level DTCANN control with neural speed controller (See Figures 2627).
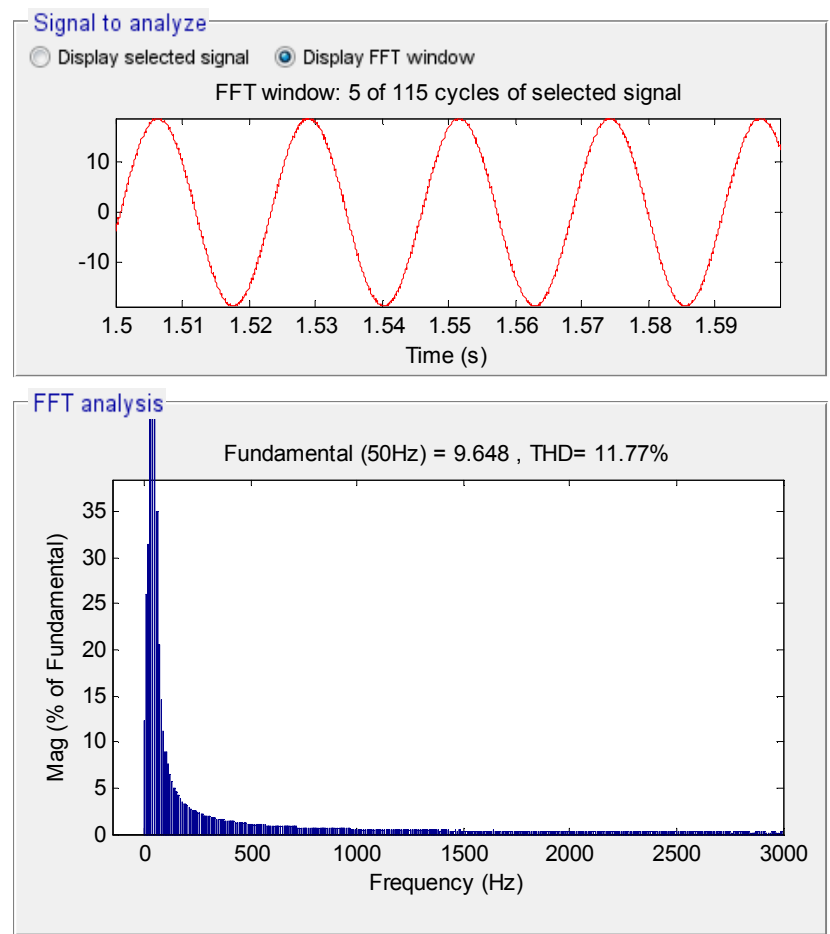

Figure 21. Spectrum harmonic of stator current (Seven-level DTC-ANNPIN). 
Habib Benbouhenni: Seven-level NPC Inverter-based Neuronal Direct Torque Control of the PMSM Drives with Regulation Speed Using Neural PI Controller

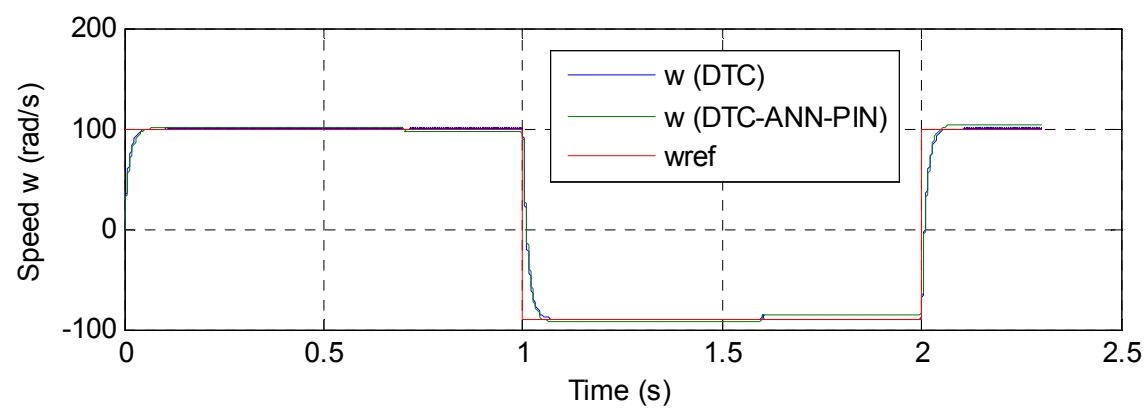

Figure 22. Speed.

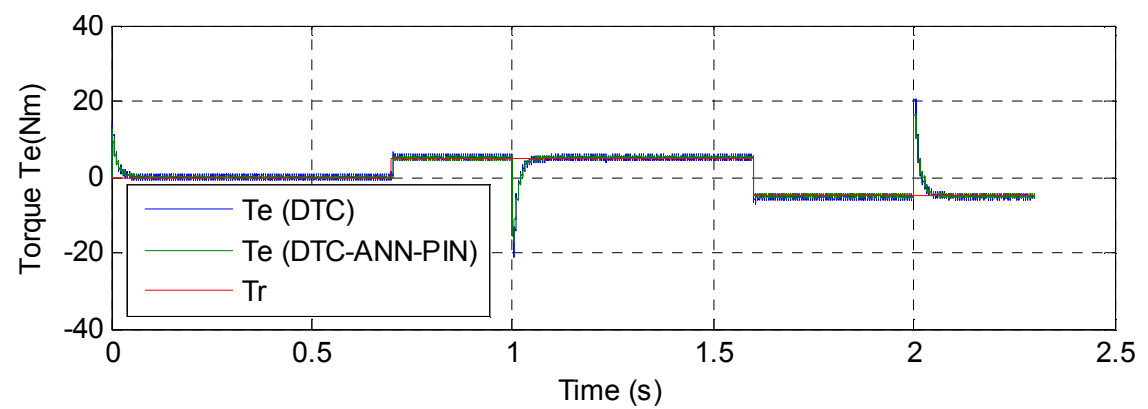

Figure 23. Torque.

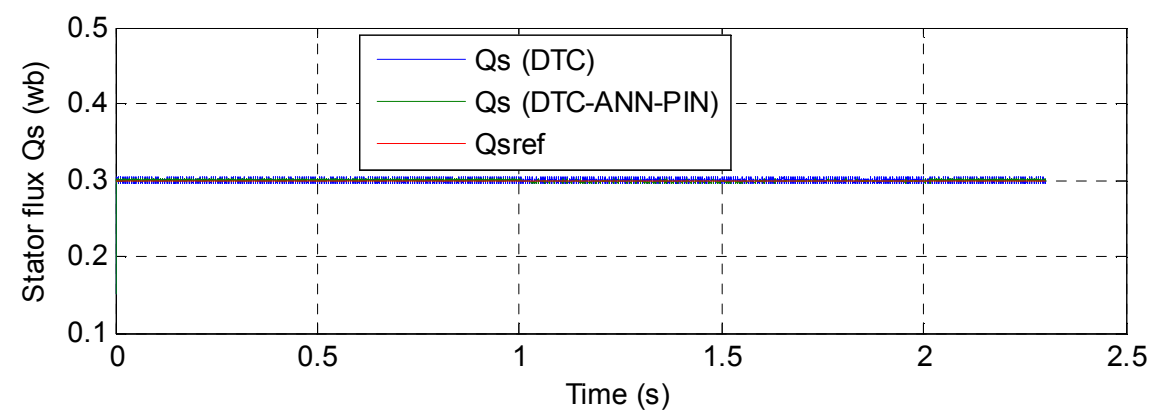

Figure 24. Stator flux.

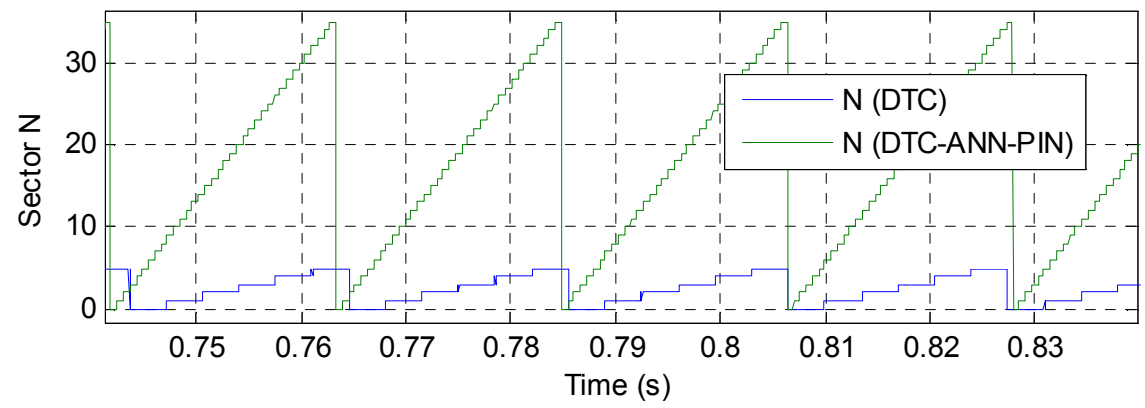

Figure 25. Sector.

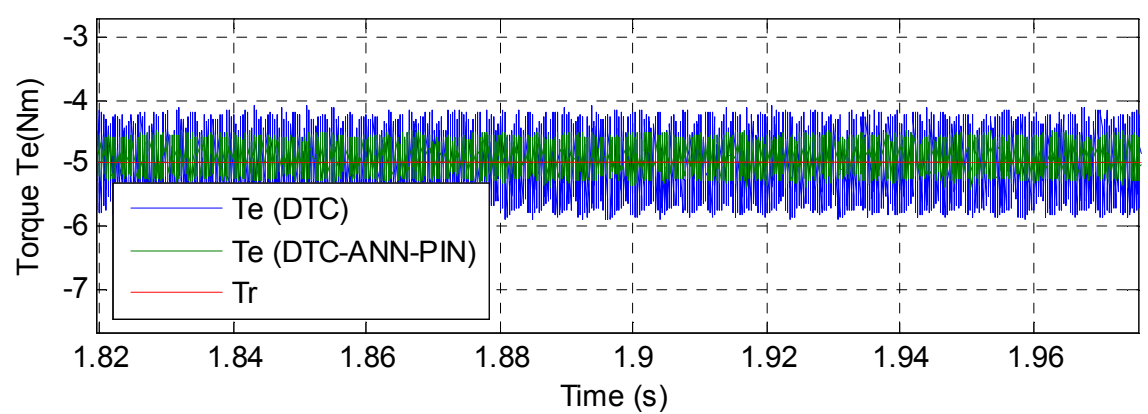

Figure 26. Zoom in the torque. 


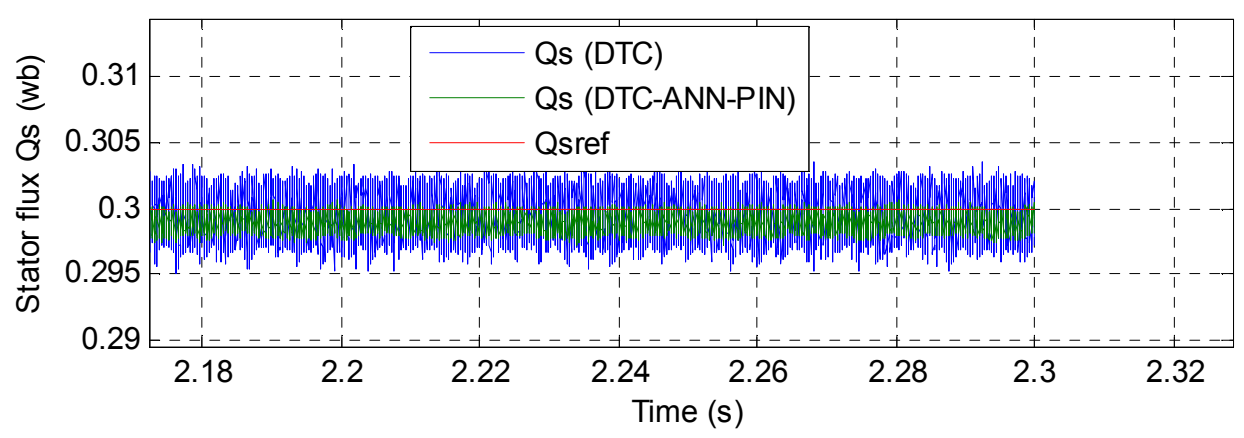

Figure 27. Zoom in the stator flux.

\section{Conclusion}

In this paper, the seven-level neural DTC with neural PI controller is presented and it is compared with traditional DTC control. The simulation results obtained for the proposed control scheme illustrate a considerable reduction in electromagnetic torque ripple, harmonic distortion of stator current and stator flux ripple compared to the conventional DTC utilizing two-level inverter and even compared with results presented in other recent works such as [14] and [22].

\section{References}

[1] R. Ilka, Y. Alinejad-Beromi, H. Yaghobi, «Geometry optimization of five-phase permanent magnet synchronous motors using bees algorithm,» Iranian Journal of Electrical \& Electronic Engineering, Vol. 11, No. 4, pp. 345-353, 2015.

[2] F. Heydari, A. Sheikholeslami, K. G. Firouzjah, S. Lesan, «Predictive field-oriented control of PMSM with space vector modulation technique,» Front. Electr. Electron. Eng., Vol. 5, No. 1, pp. 91-99, 2010, DOI: 10.1007/s11460-009-0067-1.

[3] J. Qian, C. Ji, N. Pan, J. Wu, «Improved sliding mode control for permanent magnet synchronous motor speed regulation system,» Applied Sciences, Vol. 8, pp. 1-10, 2018.

[4] A. Bechkaoui, A. Ameur, S. Bouras, D. Taibi, K. Ouamrane, «Intelligent control using type-2 fuzzy for diagnosis of interturn short circuit fault in PMSM,» Electrotehnica, Electronica, Automatica, Vol. 64, No. 1, pp. 79-88, 2016.

[5] F. Benchabane, A. Titaouine, O. Bennis, K. Yahia, D. Taibi, A. Guettaf, «Sensorless direct torque control for salient-pole PMSM based on extended Kalman filter fed by AC/DC/AC converter,» Front. Energ., Vol. 6, No. 3, pp. 247-254, 2012. https://doi.org/10.1007/s11708-012-0190-1.

[6] M. Aghasi, D. A. Khaburi, V. Faraji, H. Behnia, «A comparative study on predictive and ISVM direct torque control methods for a doubly fed induction machine fed by an indirect matrix converter,» Iranian Journal of Electrical \& Electronic Engineering, Vol. 8, No. 2, pp. 138-145, 2012.

[7] Q. Song, Y. Li, C. Jia, «A novel direct torque control method based on asymmetric boundary layer sliding mode control for PMSM,» Energies, Vol. 11, pp. 1-15, 2018.

[8] O. Ouledali, A. Meroufel, P. Wira, S. Bentouba, «Torque and stator flux ripples minimization for direct torque control of PMSM by using space vector modulation,» Majlesi Journal of
Electrical Engineering, Vol. 12, No. 3, pp. 55-61, 2018.

[9] H. Bouzeria, C. Fetha, T. Bahi, I. Abadlia, Z. Layate, S. Lekhchine, «Fuzzy logic space vector direct torque control of PMSM for photovoltaic water pumping system,» Energy Procidia, Vol. 74, pp. 760-771, 2015.

[10] F. Hicham, D. Yousfi, A. D. Youness, E. M. Larbi, N. Abd Rahim, «Sliding-mode speed control of PMSM with fuzzylogic chattering minimization-design and implementation,» Information, Vol. 6, pp. 432-442, 2015. doi: 10.3390/info6030432.

[11] H. Benbouhenni, «Seven-level direct torque control of induction motor based on artificial neural networks with regulation speed using fuzzy PI controller,» Iranian Journal of Electrical and Electronic Engineering, Vol. 14, No. 1, pp. 8594, 2018.

[12] H. Benbouhenni, «Four-level DTC with six sectors based on neural network of induction motor,» Journal Acta Electrotehnica, Vol. 58, No. 4, pp. 293-300, 2018.

[13] F. Korkmaz, M. F. Çakır, İ. Topaloğlu, R. Gürbüz, «Artificial neural network based DTC driver for PMSM,» International Journal of Instrumentation and Control Systems, Vol. 3, No. 1, pp. 1-13, 2013.

[14] J. Huang, L. Cui, X. Shi, «Direct torque control of PMSM based on fractional order sliding mode variable structure and experiment research,» International Journal of Control and Automation, Vol. 7, No. 10, pp. 217-232, 2014.

[15] M. Kadjoudj, N. Golea, M. H. Benbouzid, «Voltage switching tables for direct torque control of PMSM drive,» U.P.B. Sci. Bull., Series C, Vol. 69, No. 3, pp. 23-36, 2007.

[16] W. Liu, D. Liu, Q. Wu, Q. Lu, L. Cui, J. Wang, «Comparative study on direct torque control of interior permanent magnet synchronous motor for electric vehicole,» IFAC-Papers Online, Vol. 48, No. 11, pp. 65-71, 2015.

[17] S. Kalidasu, D. Kiran Kumar, «A matlab/simulink model of PMSM drive using direct torque control with space vector modulation,» International Journal Of Professional Engineering Studies, Vol. vi, No. 3, pp. 1-7, 2016.

[18] A. Ameur, B. Mokhtari, N. Essounbouli, L. Mokrani, «Speed sensorless direct torque control of PMSM drive using space vector modulation based MRAS and stator resistance estimator,» International Science Index, Electrical and computer Engineering, Vol. 6, No. 6, pp. 774-779, 2012.

[19] O. Oueldalli, A. Meroufel, P. Wira, S. Bentouba, «Direct torque fuzzy control of PMSM based on SVM,» Energy Procedia, Vol. 74, pp. 1314-1322, 2015. 
[20] M. Kadjoudj, S. Taibi, N. Golea, H. Benbouzid, «Modified direct torque control of permanent magnet synchronous motor drives,» International Journal of Sciences and Techniques of Automatic Control \& Computer Engineering, Vol. 1, No. 2, pp. 167-180, 2007.

[21] H. Benbouhenni, «Improved switching selection for DTC of induction motor drive using artificial neural networks, $\gg$ Acta Electrotechnica et Informatica, Vol. 18, No. 1, pp. 26-34, 2018.
[22] H. Benbouhenni, R. Taleb, «Nouveaux tableaux de commutations de la commande DTC d'une MAS alimentée par onduleur NPC à trois niveaux,» Proceedings of Engineering and Technology, Vol. 14, pp. 123-128, 2017.

[23] T. Sutikno, N. R. N. Idris, A. Jidin, «A new fixed switching frequency direct torque controlled PMSM drives with low ripple in flux and torque,» ITB J. Eng. Sci., Vol. 43, No. 3, pp. 173-190, 2011. 